\title{
Neuropsychologia \\ Word learning in two languages: Neural overlap and representational differences --Manuscript Draft--
}

\begin{tabular}{|c|c|}
\hline Manuscript Number: & NSY-D-20-00606R1 \\
\hline Article Type: & Research Paper \\
\hline Section/Category: & Language \\
\hline Keywords: & Word learning, second language acquisition, bilingualism, fMRI, prefrontal cortex \\
\hline Corresponding Author: & $\begin{array}{l}\text { Roberto A. Ferreira, PhD } \\
\text { Pontificia Universidad Católica de Chile } \\
\text { Santiago, CHILE }\end{array}$ \\
\hline First Author: & Roberto A. Ferreira, PhD \\
\hline \multirow[t]{2}{*}{ Order of Authors: } & Roberto A. Ferreira, PhD \\
\hline & David Vinson, PhD \\
\hline
\end{tabular}


Word learning in two languages: Neural overlap and representational differences

\begin{abstract}
We investigated the neural basis of newly learned words in Spanish as a mother tongue (L1) and English as a second language (L2). Participants acquired new names for real but unfamiliar concepts in both languages over the course of two days. On day 3, they completed a semantic categorization task during fMRI scanning. The results revealed largely overlapping brain regions for newly learned words in Spanish and English. However, Spanish showed a heightened BOLD response within prefrontal cortex (PFC), due to increased competition of existing lexical representations. In contrast, English displayed higher activity than Spanish within primary auditory cortex, which suggests increased phonological processing due to more irregular phonologicalorthographic mappings. Overall, these results suggest that novel words are learned similarly in Spanish L1 and English L2, and that they are represented in largely overlapping brain regions. However, they differ in terms of cognitive control and phonological processes.
\end{abstract}

Keywords: Word learning, second language acquisition, bilingualism, fMRI, prefrontal cortex 


\section{Introduction}

Given that most of the world population is bilingual (Grosjean, 2010), bilingualism is no longer the exception but rather the norm for society. An important question is how the brain learns words in the native language (L1) and the second language (L2). So far, most neuroimaging studies have revealed that similar activation is found for the processing of the L1 and L2 in the so-called language network (Briellmann et al., 2004; Cao, Tao, Liu, Perfetti, \& Booth, 2013; Costa \& Sebastián-Gallés, 2014; Kim et al., 2016; Li et al., 2019; Van de Putte, De Baene, Brass, \& Duyck, 2017; Videsott et al., 2010). However, some studies have reported differences in certain regions, which have been attributed to variables such as age of acquisition (AoA) and proficiency (Hsu, Jacobs, \& Conrad, 2015; Jamal, Piche, Napoliello, Perfetti, \& Eden, 2012; Liu \& Cao, 2016; Sun et al., 2015). While most studies have focused on understanding the processing of already-known languages in the bilingual brain, much less attention has been devoted to understanding how bilinguals encode and store new information in each of the languages they speak. The aim of the present study was to investigate how bilinguals learn new words in two languages and how these new words come to be represented in the brain.

Whether two languages are integrated in one language system or represented in two separate systems has been a core topic in bilingual research for a long time (Costa \& Sebastián-Gallés, 2014; Kroll \& Bialystok, 2013; Perani \& Abutalebi, 2005; van Heuven \& Dijkstra, 2010). The most influential behavioural models of bilingual language processing largely agree that lexica are integrated across L1 and L2 (Dijkstra \& Van Heuven, 2002; Kroll \& Stewart, 1994; Van Hell \& De Groot, 1998). There are only some differences between these models. For instance, the Revised Hierarchical Model (RHM) by Kroll and Stewart (1994) puts the emphasis on lexico-semantic links in L1 and L2, whereas the Bilingual Interactive Activation Plus (BIA +) model (Dijkstra \& Van Heuven, 2002) focuses on orthographic lexical representations in the two languages, explicitly 
assuming a shared semantic system. A third model, the distributed feature model (Van Hell \& De Groot, 1998), assumes partially overlapping semantic feature sets across languages. For instance, if a native speaker of Spanish has a representation for the word 'cena' in Spanish and then learns its English equivalent 'dinner', most of the features of the two corresponding lexical concepts would be shared, because both 'cena' and 'dinner' refer to meals that people have in the evening. However, some features of the concepts would not be shared, because the type of food eaten in Spanish speaking countries differs and also the time at which people have dinner or cena (e.g., cena usually takes place much later than dinner). Despite some differences between the models, they largely agree that representations across languages are shared or at least partially shared. But how are new words in each language integrated within the language network? Some argue that L2 words are learned via lexical mediation, which involves the activation of equivalent L1 words before L2 words can be encoded (Grainger et al., 2010; Kroll et al., 2010; Kroll \& Stewart, 1994). This might be accurate, but it does not explain the learning of completely new words in both languages. Another view suggests that learning across the native language and the L2 does not differ widely, so L2 words can be integrated without necessarily activating the L1 lexical representation (Dijkstra, Haga, Bijsterveld, \& Sprinkhuizen-Kuyper, 2012; Meade \& Dijkstra, 2017). It can be inferred then from this view that if newly learned words are to be integrated, the process should be similar across languages.

With respect to brain activity, after initial support from aphasia for the view that the languages of a bilingual are represented in different brain regions (Paradis, 1995; Paradis et al., 1982) and similar conclusions drawn from early fMRI studies (Dehaene et al., 1997), today there is consensus that languages are represented in overlapping or mostly overlapping networks, including areas within the left perisylvian cortex, frontal, temporal and parietal regions, as well as subcortical structures (Costa \& Sebastián-Gallés, 2014; Indefrey, 2006; Peeters et al., 2019). A great number 
of studies support this claim, with research showing widespread overlapping of brain regions for two or more languages at a single-word processing (Chee et al., 1999, 2003). For instance, Chee et al. (1999) examined the neural activation of Mandarin and English in bilingual speakers during cued word generation task in each language. They found activation in prefrontal, temporal, and parietal regions, as well as in the supplementary motor cortex for both languages. They found no differences in activation between the languages in these cortical regions, irrespective of age of acquisition. While the evidence showing widespread overlap is compelling, there are some studies revealing differential recruitment of areas involved in language control during L1 and L2 processing, which have been attributed to more effortful processing during L2 rather than differences in the representation of each language (e.g., Abutalebi, 2008; Luk, Green, Abutalebi, \& Grady, 2011).

Within the network of regions, an overwhelming number of studies have found higher activation in inferior frontal cortex (IFC) for L2 vs. L1 (Berken et al., 2015; Dehaene et al., 1997; Marian et al., 2007; Perani et al., 1996; Perani et al., 2003). For example, Berken et al. (2015) found that sequential bilinguals showed increased activity in left inferior frontal gyrus (IFG), premotor cortex, and fusiform gyrus when reading in English (L2) in comparison to French (L1), which suggests more effort associated with speech-motor control and orthography-to-phonology mappings. They also showed that brain activity for L2 processing in these regions correlated with age of acquisition (AoA). IFC activity has been implicated in language/cognitive control in bilingual speakers along with a number of other regions including dorsal anterior cingulate cortex, the inferior parietal lobule (IPL), and the left caudate (Abutalebi \& Green, 2007; Green \& Abutalebi, 2013, 2015). A number of other studies have reported diverging brain activation for L1 and L2 in similar regions in different groups of bilingual speakers, including Dutch-French (De 
Bleser et al., 2003), English-Chinese (Liu, Dunlap, Fiez, \& Perfetti, 2007; Nelson, Liu, Fiez, \& Perfetti, 2009), Spanish-English (Jamal et al., 2012), and Russian-English (Marian et al., 2007).

Thus, studies converge toward an integrated view of bilingualism. When differences across the two languages are observed, they are argued to come about because of variables such as AoA, language experience, cross-linguistic differences, and language proficiency (Braunstein et al., 2012; Cao et al., 2013; Perani et al., 1998; Perani et al., 2003). It is worth mentioning that all this evidence comes from studies that have compared languages individuals learned in different contexts, so it is difficult to tease apart individual and cumulative effects of AoA and proficiency on language representation (Berken et al., 2017; Birdsong \& Vanhove, 2016; Hernandez \& Li, 2007). More importantly, current models of bilingual word processing and most previous research have neglected the fundamental question of whether words in L1 and L2 are learnt in the same way, engaging the same neural networks.

In order to answer the question of learning, a word learning paradigm is better suited. So far word learning in bilinguals has hardly been studied using an ecologically valid paradigm by means of neuroimaging techniques. The present study is the first to investigate the integration of newly learned words into semantic memory in fluent bilingual speakers by means of functional magnetic resonance imaging (fMRI). Our innovative ecologically motivated approach involved a tightly controlled paradigm with extensive training sessions. We investigated whether newly learned words in Spanish (L1) and English (L2) are integrated within the same language network, and whether any differences emerge in the use of orthography or phonological processing systems and the integration of new lexical representations in semantic memory.

We make three predictions regarding the processing of newly learned words in Spanish L1 and English L2. 
- First, based on the most influential behavioural models (Dijkstra et al., 2012; Meade \& Dijkstra, 2017), we predict close similarities in the learning of new words in L1 and L2, as they should follow similar trajectories.

- Second, we predict that activation for newly learnt words in L1 and L2 will show a similar pattern across languages, engaging primarily temporal and frontal cortices of the left hemisphere (Costa \& Sebastián-Gallés, 2014; Jamal et al., 2012; Van de Putte et al., 2018). Since participants learn exactly the same concepts across languages, we do not predict differences in activation in brain regions associated with semantic representation such bilateral anterior temporal pole (Lambon Ralph et al., 2017; Patterson et al., 2007), middle temporal gyrus, and the angular gyrus (Binder et al., 2009; Binder \& Desai, 2011).

- Third, differences between Spanish L1 and English L2 are likely to be found within IFC due to differences in proficiency (Braunstein et al., 2012; Cao et al., 2013), orthographyphonology mappings $\mid$ and AoA (Berken et al., 2017) between the languages. Hence, increased activity for English newly learned words should be expected in IFC driven by increased processing effort. Since this prediction is made based on the processing of familiar words, we do not know whether such differences will emerge during learning.

In order to test these predictions, participants learn new words for unfamiliar concepts in both Spanish (L1) and English (L2) over the course of two days. On the third day, they completed a semantic categorization task (living / non-living) during fMRI scanning. We examine reaction times (RTs) and accuracy for this task, as well as brain activation for newly learned words in Spanish and English compared to baseline and direct comparisons between Spanish and English newly learned words. 


\section{Materials and methods}

\subsection{Participants}

Twenty sequential (unbalanced) Spanish-English bilinguals (11 females, 9 males; mean age = 28.6, $\mathrm{SD}=3.7$ years; Age of Acquisition of English, 8.5, $\mathrm{SD}=2.9$ ), studying at different universities in the London area, took part in the study and received payment for their participation. One female participant was excluded from the analysis due to technical problems, leaving the data from 20 participants for analysis. All individuals were right-handed (mean laterality index $=93.5, \mathrm{SD}=8.1$; Oldfield, 1971) and had normal or corrected-to-normal vision and no previous history of language disorders. They all resided in the UK and had a high English proficiency at the time they started their university programmes, as demonstrated by standardized English tests: B2 (3), C1 (12), or C2 (5) according to CEFR (Council of Europe, 2014). Participants also reported high self-ratings for English proficiency across all 4 skills $(5.6, \mathrm{SD}=0.7)$ from a maximum of 7.0 , as shown by the Language History Questionnaire (Li et al., 2006). Additionally, they were asked to take the LexTALE (Lemhöfer \& Broersma, 2012) obtaining a mean score of 76.3 (SD, 10.6) from a maximum of 100 in this test. The experiment was approved by the research ethics committee at the Birbeck-UCL Centre for Neuroimaging, London, UK.

\subsection{Stimuli}

In total, the experiment had 80 stimuli consisting of 40 familiar and 40 novel words (nouns), of which half were Spanish and half were English (see Table S1 of the Supplementary materials). All stimuli were further divided into living and non-living entities in accordance with the semantic categorization task that participants performed in the scanner. Familiar words were matched across languages on log frequency (Guasch et al., 2012; The British National Corpus, version 3 (BNC XML Edition), 2007), concreteness (Davis \& Perea, 2005; Wilson, 1988), and number of letters 
(see Table S2 of the Supplementary materials). Examples of familiar words in Spanish are cisne, lobo, balde, and rueda whereas examples of familiar English words are goat, spider, pillow, and knife.

Twenty novel words following English phonotactics and 20 following Spanish phonotactics were created and matched to familiar words on letter length, and across languages on letter length and orthographic neighbourhood (Balota et al., 2007; Davis \& Perea, 2005). Examples of the novel words are barla, endala, laro, and jadal for Spanish and clamod, smank, kentor, and calt for English. The novel words were paired to familiar but obscure concepts (half living and half nonliving), for which the real word forms were replaced with the novel words. A colour picture was associated with each novel word, and a set of 10 sentences that conveyed different semantic features. The pictures and sentences were rotated around, so one group of participants received half of the concepts in Spanish and the other half in English, while a second group received exactly the opposite arrangement. This manipulation ensured full control over the amount of meaning participants were exposed to during training across the two languages. All sentences had a Spanish and an English version, but participants were never exposed to the same concepts in both languages. Examples of the sentences used in Spanish are Un emapén es café claro y tiene los ojos rojos; La galda es un artefacto romano hecho de bronce. Examples of the sentences in English are: The sernal was discovered in Grete by an Italian archaeologist; $A$ hendor flies, eats nectar, and is attracted to light (see Table S3 of the supplementary materials). A question (e.g., what colour is a smank?, what was the sernal used for?) was introduced at the end of each block of sentences in order to make sure that participants paid attention to their content. In a survey conducted at the end of the study, none of the participants reported knowledge of the real names for the concepts either in English or Spanish. However, they did acknowledge that they resembled entities whose name they were familiar with (e.g., birds, mammals, objects, etc.). 


\subsection{Design and Procedure}

Training took place over two consecutive days in a testing room in the Experimental Psychology Department at UCL. On days 1 and 2, participants were first exposed to 20 novel concepts and words in either Spanish or English (the order was counterbalanced) and after a 5-minute break they were presented with the stimuli in the other language. Each training session lasted slightly over an hour. On the third consecutive day, participants were invited to the Birkbeck-UCL Neuroimaging Centre (BUCNI) to perform a semantic categorization task in an MRI scanner.

\subsubsection{Learning}

Participants were told that they were going to learn novel words in Spanish and English across two 1-hour sessions with a 5-minute break in between. Next, they were instructed to sit in front of a computer and put on a pair of headphones before starting the first session. Training on day 1 started with the presentation of a novel word in either Spanish or English, depending on the group participants were assigned to. Each novel word was heard over the headphones as a colour picture illustrating a concept was displayed on the screen for $4 \mathrm{~s}$ (order of presentation was randomized). Participants were instructed to say the word aloud after hearing it. Each word was then presented three times accompanied by the same colour picture. In the second part of session 1, participants were initially shown the written form of the word along with the colour picture for $3 \mathrm{~s}$. Then each word was displayed embedded within 5 sentences appearing for $8 \mathrm{~s}$ each. The sentences were always presented in the same sequential order, but the blocks were randomized. At the end of the block of sentences, a question appeared on the screen in order to prompt participants to recall specific features of the concepts (e.g., colour, size, use, etc.). Each question stayed on until participants pressed Enter and received feedback on their responses. In part 3, they were required to hear and see each novel word on the screen along with the corresponding picture. They were 
encouraged to carefully examine the picture and the written word before re-typing the novel word and press Enter to move to the next trial. In part 4 and final, the task was exactly the same as in part 1, except that participants had to type the novel word after the written word disappeared from the screen, and they were given feedback after they produced their response (see Figure 1). After a 5-minute break, participants resumed the training session in the other language and followed exactly the same procedure. On day 2 , the training session was almost identical to that of day 1 , except that in part 1 participants saw the written form of each word. The rest of the procedure was exactly the same, but the order of presentation of the block of sentences was different and new catch trials (questions) were included. The last two parts were exactly the same, except for the different random order each time.

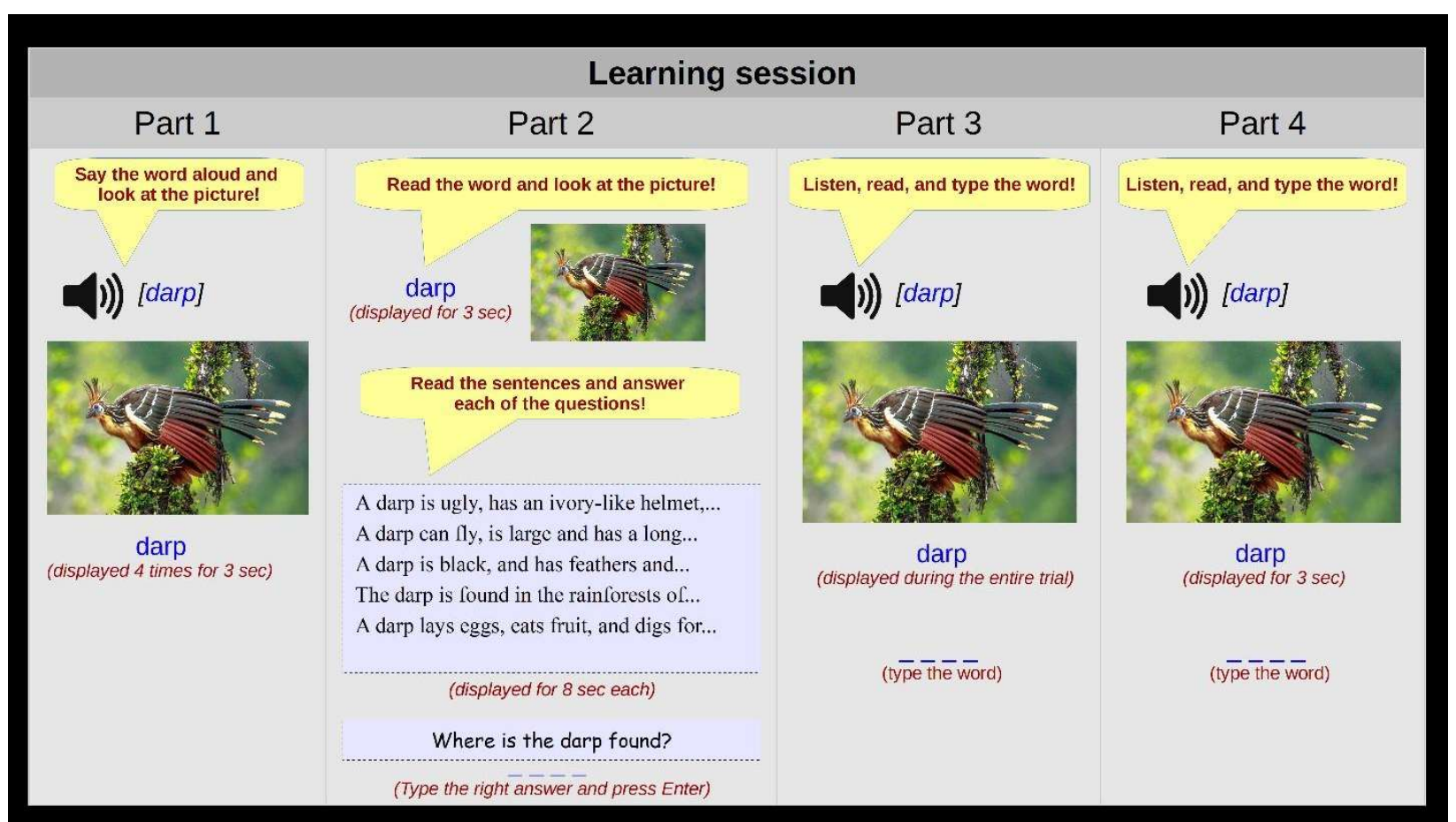

Fig. 1. Schematic overview of the learning session on Day 1 (English novel words). 


\subsubsection{Testing in the scanner}

After going through all scanning safety procedures, participants were familiarized with the semantic categorization task to be performed in the scanner and completed 10 practice trials. Once in the scanner, participants performed the task on all familiar and newly learned words divided into 2 runs - one for English and another one for Spanish. The instructions were in the language of the run they were required to perform. We used an event-related design with 40 words in each run, but each word was presented twice in order to increase statistical power. The presentation of the stimuli and response recording were carried out using the Cogent toolbox (http://www.vislab.ucl.ac.uk/Cogent) for MATLAB (The MathWorks, Inc.) on a Windows computer, a projector, and an angled mirror above the participant's head. The stimuli were presented in lower-case 50-point Courier New font in white on a black background. Each trial started with the display of a fixation cross for $500 \mathrm{~ms}$ followed by a familiar or a newly learned word which stayed on for $500 \mathrm{~ms}$. Participants were instructed to press one of two buttons to indicate whether the word on the screen was a living or non-living entity. They were also told to avoid articulating the words as they appeared on the screen. After the presentation of each word a blank screen was displayed for an average of 2,500 ms (jittered across trials).

\subsection{MRI Data Acquisition}

Whole-brain functional and structural images were acquired at the Birbeck-UCL Centre for Neuroimaging (BUCNI) using a 1.5 Siemens Avanto MRI scanner (Siemens Medical Systems, Erlangen, Germany). The fMRI data were acquired using a 32-channel coil with a multiband echoplanar imaging $(\mathrm{EPI})$ sequence $\left(\mathrm{TR}=1000 \mathrm{~ms}, \mathrm{TE}=54.8 \mathrm{~ms}\right.$, flip angle $=75^{\circ}, \mathrm{FOV}=192 \times 192$, matrix $=64 \times 64$, voxel size $=3 \times 3 \times 3 \mathrm{~mm}$ ), with an interleaved acquisition order. High resolution T1-weighted structural images were obtained by means of a gradient-echo pulse sequence $(\mathrm{TR}=$ 
$2730 \mathrm{~ms}, \mathrm{TE}=3.57 \mathrm{~ms}$, inversion time $(\mathrm{TI})=1000 \mathrm{~ms}$, flip angle $=7^{\circ}, \mathrm{FOV}=256 \mathrm{~mm}$, slice thickness $=1 \mathrm{~mm}$ )

\subsection{Pre-processing}

Pre-processing and analysis of functional images for each participant were carried out using FEAT v 6.00, the FMRI Expert Analysis Tool in FSL 5.0.7 (the FMRIB Software Library) (Jenkinson et al., 2002). Trials used in the analysis corresponded to each stimulus's onset time, that is, from stimulus presentation to when the participant made the response by pushing a button on the response box (Grinband et al., 2008). The fMRI analysis and the RT analysis were performed on exactly the same trials, which included only correct responses (including RTs above $300 \mathrm{~ms}$ and below 2.5 SDs from the mean for each condition and presentation). During data pre-processing, images were realigned for motion correction using MCFLIRT and sliced-time corrected with Fourier-space time series phase-shifting. An 8 mm full-width high maximum (FWHM) Gaussian kernel was used for spatial smoothing, and Gaussian-weighted least-squares straight line fitting with sigma $=50 \mathrm{~s}$ was employed for high pass temporal filtering. Registration to high-resolution participant's T1 images and standard space was carried out using FMRIB's linear registration tool FLIRT (Jenkinson \& Smith, 2001; Jenkinson et al., 2002).

In first-level processing, a general linear model (FILM) time-series analysis was conducted using local autocorrelation correction (Woolrich et al., 2001). The data from each participant in each condition (20 familiar Spanish words, 20 familiar English words, 20 newly learned Spanish words, and 20 newly learned English words) were entered into a general linear model for eventrelated analysis with each condition implicitly modelled against rest. Two regressors were also added to account for variations in order of presentation and RT. This was motivated by the findings that RTs tended to be faster to second than first presentations of the stimulus words, and that there 
were possible domain-general effects due to performance differences in response time across conditions.

At second-level and combining both runs (Spanish and English), each of the comparisons of interest (familiar Spanish vs. familiar English, and newly learned Spanish vs. newly learned English) was analysed using paired samples t-tests. Third-level analyses were then conducted across the 20 participants using FLAME Bayesian mixed-effects analysis (Beckmann et al., 2003; Woolrich et al., 2001) aiming at generating z-statistics based on the contrasts between the conditions presented above.

FMRI data processing was carried out using FEAT (FMRI Expert Analysis Tool) Version 6.00, part of FSL (FMRIB's Software Library, www.fmrib.ox.ac.uk/fsl). Z (Gaussianised T/F) statistic images were thresholded using clusters determined by $Z>2.3$ and a (corrected) cluster significance threshold of $p=.05$ (Forman et al., 1995; Worsley, 2001). Peaks of activation falling more than 8 $\mathrm{mm}$ apart are reported separately. When peaks were separated by less than $8 \mathrm{~mm}$, only the highest peak is reported. Areas of activation were labelled with the help of the Harvard-Oxford Cortical Structure Atlas and the Harvard-Oxford Subcortical Structure Atlas incorporated into FSL view (Oxford Centre for Functional MRI of the Brain (FMRIB) Software Library; www.fmrib.ox.ac.uk/fsl). All coordinates are in MNI space (Evans et al., 1992).

\subsection{Behavioural data analyses}

Linear mixed-effects models with crossed random effects for participants and items (Baayen et al., 2008) were used to analyse the data for RTs and errors. This was carried out using the lme 4 package version 1.1-7 (Bates et al., 2015) on R version 3.1.1. (R Core Team, 2017). Random intercepts and random slopes by participants and by items for language (Spanish, English) and familiarity (familiar, newly learned) were included in the analyses. In order to make sure that 
interactions were orthogonal to the main effects, we contrast-coded all fixed effects. We report the relevant statistics and corresponding coefficient estimates (CE) for both RTs and error analyses, including $p$-values obtained using the LmerTest package (Kuznetsova et al., 2017).

\section{Results}

\subsection{In-Scanner behavioural data}

The 20 participants in the study produced 3200 responses from which $252(7.9 \%)$ corresponded to miscategorizations and 90 were no responses $(2.8 \%)$. The remaining $2858(89.3 \%)$ responses were considered for analysis. A summary of the data collected in the scanner is presented in Table 1.

\section{Table 1}

Mean RTs in ms (with SDs) and error rates in the semantic categorization task as a function of language and familiarity.

\begin{tabular}{llclc}
\hline & \multicolumn{3}{c}{ Spanish } & English \\
\cline { 2 - 5 } & Familiar & Newly-learned & Familiar & Newly-learned \\
\hline Mean & 960 & 1306 & 1020 & 1220 \\
SD & 266 & 425 & 312 & 379 \\
$\%$ errors & 3.5 & 18.5 & 5.9 & 14.9 \\
\hline
\end{tabular}

The results of the linear mixed-effects model on RTs showed no effect of language $(\mathrm{CE}=$ 10.17, $\mathrm{SE}=23.80, t=0.43, p=.659)$, but a significant familiarity effect $(\mathrm{CE}=-279.45, \mathrm{SE}=$ 23.79, $t=-11.74, p<.001)$ and an interaction between the factors $(\mathrm{CE}=-145, \mathrm{SE}=47.59, t=-$ $3.06, p=.003$ ). Given this result, we fitted two new models to the data (one to familiar and one to 
newly learned words) in order to break down the interaction. The model applied to familiar words revealed faster RTs for Spanish than English $(\mathrm{CE}=-64.07, \mathrm{SE}=28.40, t=-2.26, p=.030)$, whereas the model used for newly learned words showed a reverse effect, that is, faster RTs for English than Spanish $(\mathrm{CE}=83.84, \mathrm{SE}=38.65, t=2.17, p=.036)$. The last model was fitted to the error data and showed no effect of language $(\mathrm{CE}=0.01, \mathrm{SE}=0.19 t=-0.33, p=.740)$, a highly significant familiarity effect, with familiar words responded to more accurately than newly learned words (CE $=0.12, \mathrm{SE}=0.19, t=6.38, p<.001)$, and no interaction between the main factors $(\mathrm{CE}=0.06, \mathrm{SE}$ $=0.04 t=1.60, p=.115$ ). See Figure 2 .

A. $\mathrm{RT}$

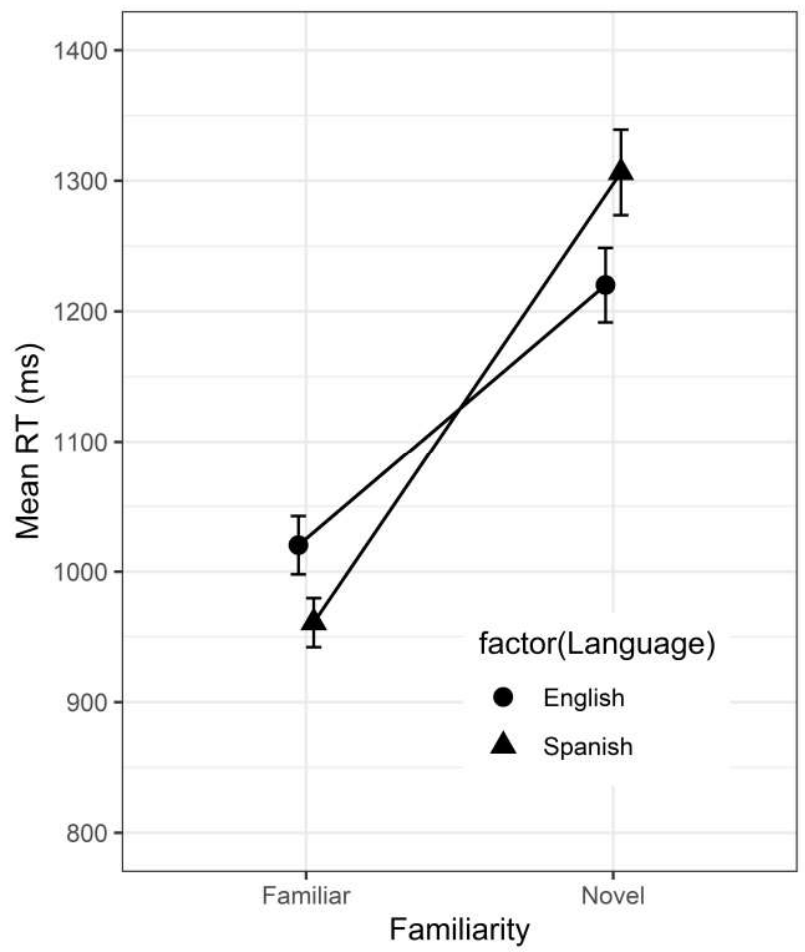

B. Accuracy

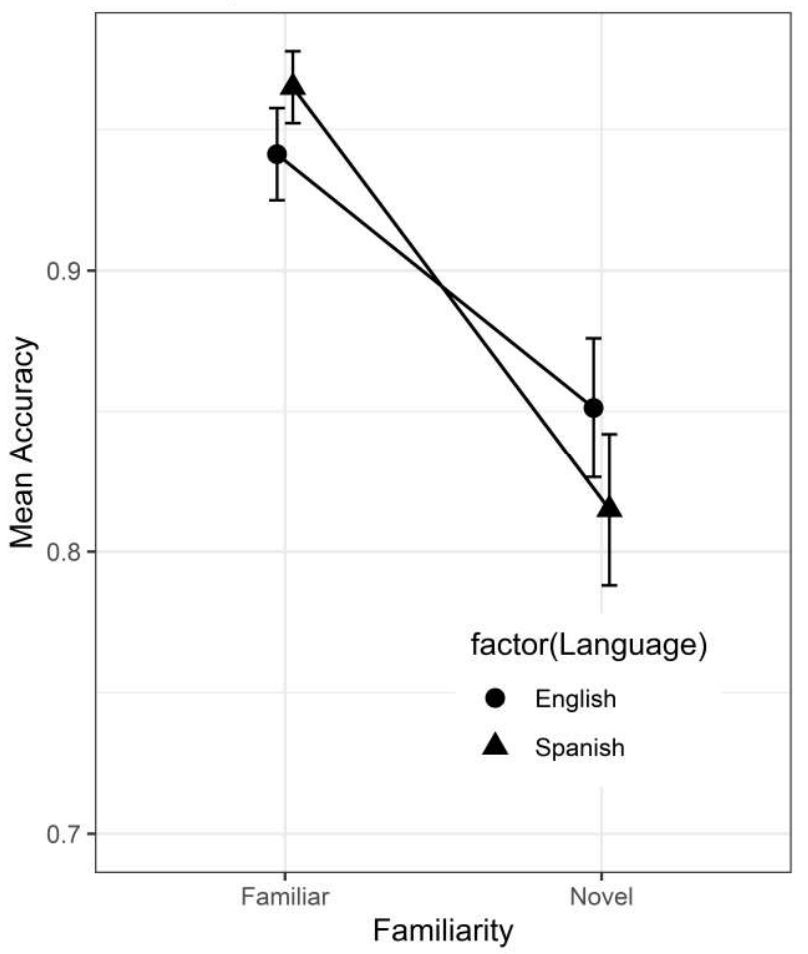

Fig. 2. Reaction times (RTs) and accuracy in the semantic categorization task in the scanner.

\subsection{Imaging Data}


Whole-brain analysis was based on the same trials used in RT analysis. BOLD responses were first compared for familiar Spanish vs. familiar English words and then for newly learned Spanish and newly learned English words. Whole-brain analyses were corrected for multiple comparisons ( $p$ $<.05)$.

Familiar Spanish and familiar English words activated similar brain regions including clusters in inferior frontal and medial frontal cortices, occipito-temporal regions, and inferior parietal lobule, among others. Activation was higher for Spanish than English in 6 clusters including (1) bilateral superior frontal gyrus, paracingulate gyrus, frontal pole and superior frontal gyrus; (2) left lateral occipital cortex and angular gyrus; (3) left supramarginal extending into lateral occipital cortex, superior temporal gyrus, middle temporal gyrus and angular gyrus; (4) left praecuneus and posterior cingulate gyrus; (5) left temporal pole and frontal orbital cortex; and (6) left parahippocampal gyrus and left hippocampus. No significant clusters were found for the reverse contrast English $>$ Spanish (see Table 2 and Supplementary Fig. S1).

\section{Table 2}

MNI Coordinates for peak voxels showing increased activity for Familiar Spanish vs. familiar English words.

\begin{tabular}{|c|c|c|c|c|c|}
\hline \multirow[b]{2}{*}{ Activation loci } & & & \multicolumn{3}{|c|}{ Coordinates (MNI) } \\
\hline & $\begin{array}{c}\text { Cluster size } \\
\text { (voxels) }\end{array}$ & $Z$ & $x$ & $y$ & $z$ \\
\hline
\end{tabular}

\section{Familiar Spanish $>$ English}

Bilateral frontal cortex

5807

R. superior frontal gyrus

4.42

$4 \quad 54$

30 
L. superior frontal gyrus

R. paracingulate gyrus

L. frontal pole

L. superior frontal gyrus

L. superior frontal gyrus

Left Lateral occipital cortex/angular gyrus

L. superior lateral occipital cortex

L. angular gyrus

L. inferior lateral occipital cortex

Right occipito-temporo-parietal junction

R. posterior supramarginal gyrus

R. superior lateral occipital cortex

R. posterior superior temporal gyrus

R. middle temporal gyrus

R. middle temporal gyrus

R. angular gyrus

Bilateral praecuneus/posterior cingulate gyrus

R. praecuneus

L. praecuneus

R. praecuneus

R. praecuneus

L. Posterior cingulate gyrus $\begin{array}{llll}4.34 & -14 & 36 & 46\end{array}$

$\begin{array}{llll}4.33 & 4 & 54 & 4\end{array}$

$\begin{array}{llll}4.16 & -16 & 50 & 32\end{array}$

$\begin{array}{llll}4.14 & -24 & 28 & 48\end{array}$

$\begin{array}{llll}4.09 & -10 & 36 & 50\end{array}$

2812

$\begin{array}{rrrr}4.45 & -36 & -70 & 24 \\ 4.15 & -56 & -54 & 16 \\ 3.94 & -52 & -64 & 8\end{array}$

2707

$\begin{array}{llll}4.29 & 52 & -44 & 14\end{array}$

$\begin{array}{llll}4.15 & 56 & -60 & 24\end{array}$

$\begin{array}{llll}4.12 & 60 & -36 & -10\end{array}$

$\begin{array}{llll}4.06 & 48 & -58 & 12\end{array}$

$\begin{array}{llll}4.04 & 60 & -46 & 6\end{array}$

$\begin{array}{llll}4.03 & 56 & -58 & 20\end{array}$

2673

$\begin{array}{llll}4.51 & 6 & -58 & 50\end{array}$

$\begin{array}{llll}4.32 & -2 & -62 & 46\end{array}$

$\begin{array}{llll}4.22 & 8 & -54 & 38\end{array}$

$\begin{array}{llll}3.99 & 20 & -56 & 12\end{array}$

$\begin{array}{llll}3.91 & -6 & -48 & 36\end{array}$ 
L. temporal pole

L. frontal orbital cortex

L. temporal pole

L. temporal pole

L. temporal pole

L. frontal orbital cortex

Parahippocampal gyrus/hippocampus

L. anterior parahippocampal gyrus

L. hippocampus

L. parahippocampal gyrus

Familiar English $>$ Spanish

No significant clusters were found.

Note: L. left; R. right.

Regarding newly learned words, Spanish and English activated largely overlapping brain regions including prefrontal cortex, with more extended activation on the left hemisphere, middle frontal gyrus, motor cortex, occipitotemporal regions, and the cerebellum (see Figure $3 \mathrm{~A}$ and $\mathrm{B}$, and Supplementary Table S4. For the contrast English $<$ Spanish, a significant cluster was found within right planum polare, posterior temporal pole, insular cortex, Heschl's gyrus, and central operculum cortex. In the contrast Spanish $<$ English, higher activation was found within left prefrontal cortex including left inferior frontal gyrus (pars opercularis and triangularis), precentral gyri, and middle frontal gyrus (see Table 3 and Figure $3 \mathrm{C}$ and D). 
Table 3

MNI Coordinates for Peak Voxels Showing Increased Activity for newly learned Spanish vs. English words.

\begin{tabular}{|c|c|c|c|c|c|}
\hline \multirow{2}{*}{ Activation loci } & & \multirow[b]{2}{*}{$Z$} & \multicolumn{3}{|c|}{ Coordinates (MNI) } \\
\hline & (voxels) & & $x$ & $y$ & $z$ \\
\hline \multicolumn{6}{|l|}{ Newly learned English > Spanish } \\
\hline Right Fronto-temporal cortex & 297 & & & & \\
\hline R. planum polare & & 3.67 & 50 & 4 & -6 \\
\hline R. posterior temporal pole & & 3.5 & 48 & 8 & -10 \\
\hline R. insular cortex & & 3.25 & 38 & 8 & -4 \\
\hline R. Heschl's Gyrus (includes H1 and H2) & & 3.02 & 46 & -16 & 10 \\
\hline \multicolumn{6}{|l|}{ Newly learned Spanish > English } \\
\hline Prefrontal/middle frontal cortex & 443 & & & & \\
\hline L. inferior frontal gyrus (pars opercularis) & & 3.46 & -54 & 16 & 28 \\
\hline L. middle frontal gyrus & & 3.42 & -40 & 14 & 44 \\
\hline L. middle frontal gyrus / posterior pars & & & & & \\
\hline triangularis & & 3.37 & -44 & 28 & 30 \\
\hline L. precentral gyrus & & 3.23 & -58 & 10 & 32 \\
\hline L. middle frontal gyrus & & 3.15 & -36 & 12 & 54 \\
\hline
\end{tabular}


A.
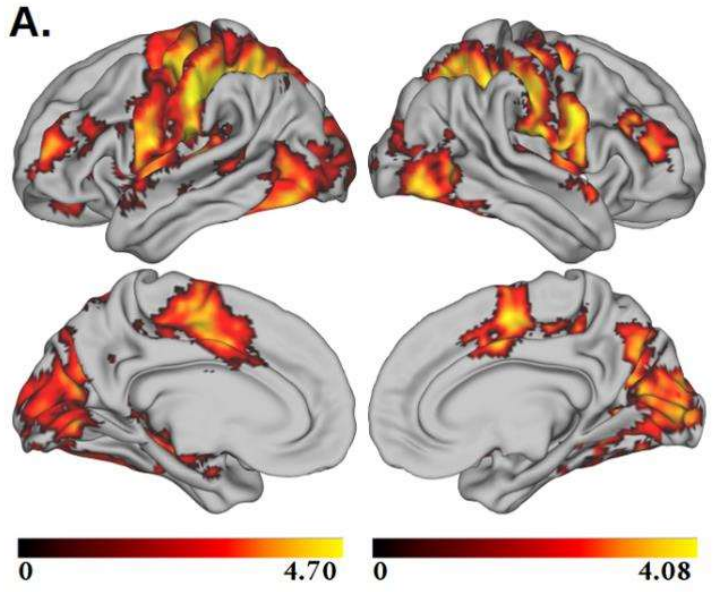

c.

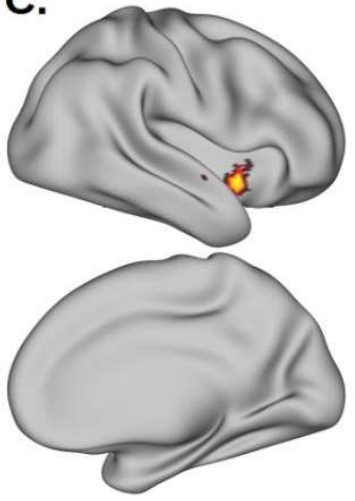

0
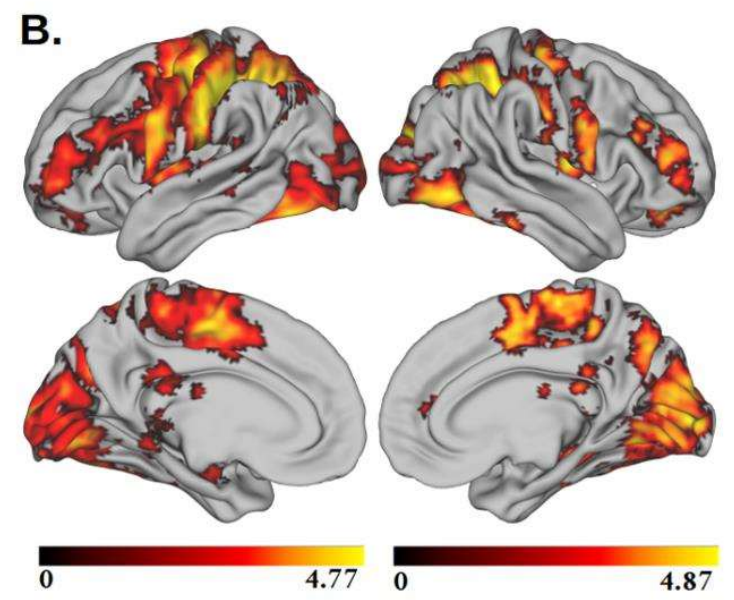

D.
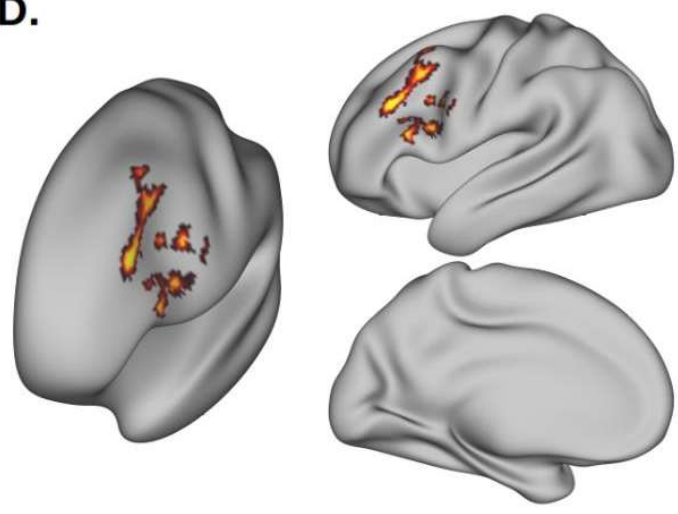

0

2.93

Fig. 3. Whole brain analysis of newly learned words in English and Spanish. Brain regions showing increased activation for A. English vs. baseline, and B. Spanish vs. baseline. C. Areas showing higher activation for English than Spanish. D. Regions showing heightened BOLD response to Spanish than English newly learned words.

\section{Discussion}

This study investigated the neural underpinnings of newly learned words in Spanish (L1) and English (L2) in fluent bilingual speakers. It is the first study to investigate how novel words are learned in two languages. The advantage of this paradigm is that it allows for the control of 
variables such as age/order of acquisition, frequency of use, proficiency, and language experience, which are difficult to control by simply comparing words already familiar to the bilinguals in both languages. After two training sessions in which participants learned novel words over two days, they performed a semantic categorization task in an MRI scanner. Participants categorized newly learned words and familiar words in Spanish and English with respect to a semantic variable (animacy). Performance in the task reached $95.6 \%$ for familiar words and $84.3 \%$ for newly learned words, which indicates that participants learned the novel words during training fairly well. We discuss the results in view of the predictions stated, with a focus on neural overlap and differences across languages.

\subsection{Overlapping representations across newly learned words in L1 and L2}

In line with our first prediction, the behavioural results of the semantic categorization task in the scanner showed no differences in accuracy across languages, which suggests close similarities in the integration of newly learned words in L1 and L2, as proposed by models of L2 acquisition (Dijkstra et al., 2012; Meade \& Dijkstra, 2017). Our findings also fit in well with behavioural models of word processing, since they all agree that lexicons are integrated across languages (Dijkstra \& Van Heuven, 2002; Dijkstra et al., 2019; Kroll \& Stewart, 1994; Van Hell \& De Groot, 1998). The RT data, however, showed a slight advantage for newly learned English words, which has implications for neural representation. We discussed these differences in the next section.

In agreement with the accuracy results and our second prediction, we found that newly learned Spanish and English words activated largely overlapping brain regions including classical language areas along bilateral prefrontal cortex (inferior frontal gyrus), with more extended activation on the left hemisphere; middle frontal gyrus, motor cortex; occipitotemporal regions; and bilateral cerebellum. The main neuroimaging models postulate a similar organization of lexico- 
semantic representations across languages (Green, 2003; Paradis, 2004, 2009; Ullman, 2001, 2005). Our results are mostly in line with the predictions and assumptions of these models; here we provide evidence on the processing of newly learned words in Spanish L1 and English L2. It is true that previous findings on existing words in L1 and L2 have shown some discrepancy across studies, but these differences have been attributed mainly to lack of control of variables such as AoA, language experience, and language proficiency (Braunstein et al., 2012; Cao et al., 2013; Perani et al., 1998; Perani et al., 2003), and even tasks or analyses (Van de Putte et al., 2017). This is further supported by examining our own results for familiar words. Familiar Spanish words showed more extensive activation than familiar English words within the semantic processing network, including medial frontal regions, middle temporal areas, bilateral angular gyrus, and praecuneus. These differences in activation can be explained by differences in knowledge of existing Spanish and English words. Spanish was participants' mother tongue and proficiency was indeed higher for Spanish than English, as reported by participants themselves in the Language History Questionnaire (7 on average for Spanish; 5.6 for English) (Li et al., 2006). Hence, the increased activity for Spanish vs. English is associated to more extensive semantic representations in L1, since these regions have previously been associated with semantic processing (Binder \& Desai, 2011; Binder, Desai, Graves, \& Conant, 2009; Vigliocco et al., 2014). Similarly, in a recent study, words associated with more semantic features showed increased activity in similar regions, which was associated to more extended semantic representation (Ferreira et al., 2015). The differences in neural representation across familiar Spanish vs. English words were also mirrored in the behavioural data, with faster RTs for familiar Spanish than familiar English words.

\subsection{Neural differences between newly learned words in L1 and L2}


Two contrasts were performed to examine differences between newly learned Spanish and English words. Contrary to our third prediction, the results revealed higher activation within left inferior frontal gyrus (pars opercularis and triangularis), middle frontal gyrus, and insular cortex for Spanish L1 than English L2. The reverse contrast (newly learned English > newly learned Spanish) showed higher activation for English in right primary auditory cortex including Heschl's gyrus and planum polare, which was a novel finding. We discuss each of these results in separate sections.

\subsubsection{Newly learned Spanish > newly learned English words}

Even though there was no difference in accuracy between Spanish and English newly learned words, RTs were significantly faster for the latter. With regards to brain regions, significant activations were located within the prefrontal cortex. Increased activation in this area has long been associated with cognitive control processes (Abutalebi, 2008; Abutalebi \& Green, 2007). There is also neuropsychological evidence relating left inferior frontal gyrus (LIFG) to deficit in the control of linguistic and semantic information (Jefferies, 2013). More specifically, studies have suggested that prefrontal activation has an important role in the selection of information among competing items in semantic memory (Nagel et al., 2008; Thompson-Schill et al., 1997; Wagner et al., 2001). Some have further proposed that the mid ventrolateral prefrontal cortex (VLPFC), which roughly corresponds to pars triangularis or BA 45, responds more strongly when selection demands are high rather than low (Badre et al., 2005; Badre \& Wagner, 2007). In the neuroanatomical model of semantic processing by Binder and Desai (2011), regions of inferior prefrontal cortices have been explicitly assigned the function of "control of goal-directed activation and the selection of information previously stored in temporoparietal areas". We propose that learning words in L1 and L2 does not differ widely, as revealed by extensive overlapping activation and small differences in RT but not accuracy in the semantic categorization task across languages. We believe differences 
in lexicon size between L1 and L2, due to the unbalanced proficiency of the participants, may have affected the storage of new lexical representations and later retrieval of the items. A more densely populated lexicon for Spanish might imply that storing new words in semantic memory involved creating links with more existing words in Spanish L1 than in English L2. These differences during learning were later reflected during retrieval in the scanner. The activation of more existing semantic and phonological or orthographic neighbours in Spanish L1 than English L2 produced more competition for newly learned words, slowing down RTs and increasing control processes associated to selection demands (Abutalebi, 2008; Badre et al., 2005; Badre \& Wagner, 2007).

There is evidence that both semantic neighbourhood density (SND) and orthographic neighbourhood affect word processing (Bowers et al., 2005; Durda \& Buchanan, 2008; Mirman \& Magnuson, 2008). For instance, Mirman and Magnuson (2008) found that words with many nearsemantic neighbours produced slower RTs relative to words with few near neighbours in a semantic categorization task. The authors attributed this phenomenon to more neighbours producing increase competition effects from semantically similar words. Similarly, in another study, Bowers et al. (2005) found that many orthographic neighbours can slow down word recognition, with respect to few orthographic neighbours. Bowers and colleagues concluded that words with many neighbours have the advantage of generating more lexical activity than words with small neighbourhood. However, when unique identification is needed, as in the present study, neighbourhood similarity slows down performance.

\subsubsection{Newly learned English > Newly learned Spanish words}


A novel result in the present study was the increased activity for English in right primary auditory cortex including Heschl's gyrus and planum polare. Portions of auditory cortex such as Heschl's gyrus have previously been associated with efficiency in the processing of speech-related cues, which can facilitate the learning and perception of new speech sounds (Warrier et al., 2009). This region also responds more strongly to unprimed vs. phonologically primed words and nonwords (Gagnepain et al., 2008), so it seems particularly engaged when phonological processing is more challenging or less fluent. This may have been the case in the present study, due to the deeper orthography of English relative to Spanish.

An alternative account is that processing was more challenging because English was the participants' second language, so they were less familiar with the English sound system. In this scenario, the problem might arise at lower-level phonology, involving difficulty in the retrieval of phonological or even acoustic features in L2 associated with the written word. This fits in well with the activation found in planum polare, which has been linked to low-level phonological processing, showing greater activity during non-phonemic trials compared to phonemic trials (Humphries et al., 2014). It is worth mentioning that previous studies have outlined other regions where differences between Spanish and English are present (Jamal et al., 2012). However, Jamal et al. (2012) tested participants on the processing of existing words, so unique activation for English in MFG and fusiform gyrus for Spanish in left MTG might reflect differences in language experience and not that language systems differ in bilingual speakers.

In accordance with our findings, we propose that the regularity of Spanish produces faster learning of phonological-orthographic mappings, which is reflected in more fluent phonological processing and decreased activity in regions involved with speech related features. Although we explicitly selected regular nonwords in English, the pronunciation of these nonwords was still ambiguous due to high irregularity present in the English language. For instance, the most regular 
pronunciation of the novel word peadle was /pi:dəl/, however, it could also be pronounced /p3:dəl/. By contrast, in Spanish, irregularities like this do not really exist, since a novel word such as jadal will always be pronounced /ha:'ða:1/. In sum, the current finding can be explained by crosslinguistic differences given that Spanish and English challenge the brain in different ways.

\section{Conclusion}

The present study investigated word learning in L1 and L2 under tightly controlled conditions in order to tap into neural overlap and neural differences of newly learned words in two languages. We found that newly learned words in Spanish L1 and English L2 are stored in largely overlapping brain regions of bilateral prefrontal cortex (inferior frontal gyrus), middle frontal and motor cortices, occipitotemporal regions, and bilateral cerebellum. The minor differences in neural activation observed can be attributed to higher selection demands in IFC due to increased competition of lexical neighbours, which are more abundant in L1 than in L2. Higher activity in auditory cortex may be the result of more effortful processing of English than Spanish newly learned words due to less transparent orthographic-phonological mappings in English. Our results shed new light on the neural representation of two languages in the bilingual brain, by examining newly learned words that participants had no prior experience with. The current findings, by and large, fit the proposals of both behavioural and neuroimaging models and advance the understanding of the word learning mechanisms involved in L1 and L2. Examining the processing of existing words in the bilingual brain has the obvious limitation that the context in which languages are learned is rarely the same. Given the number of variables that can affect results when comparing existing words across languages, our word learning paradigm offers a better alternative to test hypotheses on neural representation in L1 and L2 than simply studying existing words. New studies looking at specific aspects of L1 and L2 processing should consider using a word learning 
paradigm that is also ecologically motivated where participants are exposed to novel words in natural language contexts, instead of using highly artificial tasks that are hard to extrapolate to realworld situations.

\section{References}

Abutalebi. (2008). Acquisition, processing and loss of L2: Functional, cognitive and neural perspectives. Journal of Neurolinguistics, 21(6), 473-476. https://doi.org/10.1016/j.jneuroling.2008.10.001

Abutalebi, J., \& Green, D. (2007). Bilingual language production: The neurocognition of language representation and control. Journal of Neurolinguistics, 20(3), 242-275. https://doi.org/10.1016/j.jneuroling.2006.10.003

Baayen, R. H., Davidson, D. J., \& Bates, D. M. (2008). Mixed-effects modeling with crossed random effects for subjects and items. Journal of Memory and Language, 59(4), 390-412.

Badre, D., Poldrack, R. A., Paré-Blagoev, E. J., Insler, R. Z., \& Wagner, A. D. (2005). Dissociable controlled retrieval and generalized selection mechanisms in ventrolateral prefrontal cortex. Neuron, 47(6), 907-918. https://doi.org/10.1016/j.neuron.2005.07.023

Badre, D., \& Wagner, A. D. (2007). Left ventrolateral prefrontal cortex and the cognitive control of memory. Neuropsychologia, 2883-2901. https://doi.org/10.1016/j.neuropsychologia.2007.06.015

Balota, D. A., Yap, M. J., Hutchison, K. A., Cortese, M. J., Kessler, B., Loftis, B., Neely, J. H., Nelson, D. L., Simpson, G. B., \& Treiman, R. (2007). The English Lexicon Project. Behavior Research Methods, 39(3), 445-459. https://doi.org/10.3758/BF03193014

Bates, D., Maechler, M., Bolker, B., \& Walker, S. (2015). Linear mixed-effects models using “Eigen” and S4. http://CRAN.R-project.org/package=lme4

Beckmann, C. F., Jenkinson, M., \& Smith, S. M. (2003). General multilevel linear modeling for group analysis in FMRI. Neuroimage, 20(2), 1052-1063. 
Berken, J. A., Gracco, V. L., Chen, J.-K., Watkins, K. E., Baum, S., Callahan, M., \& Klein, D. (2015). Neural activation in speech production and reading aloud in native and non-native languages. NeuroImage, 112, 208-217. https://doi.org/10.1016/j.neuroimage.2015.03.016

Berken, J. A., Gracco, V. L., \& Klein, D. (2017). Early bilingualism, language attainment, and brain development. $\quad$ Neuropsychologia, $\quad 98, \quad 220-227$. https://doi.org/10.1016/j.neuropsychologia.2016.08.031

Binder, J. R., \& Desai, R. H. (2011). The neurobiology of semantic memory. Trends in Cognitive Sciences, 15(11), 527-536. https://doi.org/10.1016/j.tics.2011.10.001

Binder, J. R., Desai, R. H., Graves, W. W., \& Conant, L. L. (2009). Where is the semantic system? A critical review and meta-analysis of 120 functional neuroimaging studies. Cerebral Cortex, 19(12), 2767-2796.

Birdsong, D., \& Vanhove, J. (2016). Age of second-language acquisition: Critical periods and social concerns. In E. Nicoladis \& S. Montanari (Eds.), Bilingualism Across the Lifespan: Factors Moderating Language Proficiency. American Psychological Association and Walter de Gruyter GmbH.

Bowers, J. S., Davis, C. J., \& Hanley, D. A. (2005). Interfering neighbours: The impact of novel word learning on the identification of visually similar words. Cognition, 97(3), B45-B54.

Braunstein, V., Ischebeck, A., Brunner, C., Grabner, R. H., Stamenov, M., \& Neuper, C. (2012). Investigating the influence of proficiency on semantic processing in bilinguals: an ERP and ERD/S analysis. Acta Neurobiologiae Experimentalis, 72(4), 421-438.

Briellmann, R. S., Saling, M. M., Connell, A. B., Waites, A. B., Abbott, D. F., \& Jackson, G. D. (2004). A high-field functional MRI study of quadri-lingual subjects. Brain and Language, 89(3), 531-542. https://doi.org/10.1016/j.band1.2004.01.008

Cao, F., Tao, R., Liu, L., Perfetti, C. A., \& Booth, J. R. (2013). High proficiency in a second language is characterized by greater involvement of the first language network: Evidence from Chinese learners of English. Journal of Cognitive Neuroscience, 25(10), 1649-1663. https://doi.org/10.1162/jocn_a_00414 
Chee, M. W. L., Tan, E. W. L., \& Thiel, T. (1999). Mandarin and English single word processing studied with functional magnetic resonance imaging. The Journal of Neuroscience, 19(8), $3050-3056$.

Chee, M. W. L., Westphal, C., Goh, J., Graham, S., \& Song, A. W. (2003). Word frequency and subsequent memory effects studied using event-related fMRI. NeuroImage, 20(2), 10421051. https://doi.org/10.1016/S1053-8119(03)00335-5

Costa, A., \& Sebastián-Gallés, N. (2014). How does the bilingual experience sculpt the brain? Nature Reviews Neuroscience, 15(5), 336-345. https://doi.org/10.1038/nrn3709

Council of Europe. (2014). The Common European Framework of Reference for Languages: Learning, Teaching, Assessment (CEFR). Cambridge University Press.

Davis, C. J., \& Perea, M. (2005). BuscaPalabras: A program for deriving orthographic and phonological neighborhood statistics and other psycholinguistic indices in Spanish. Behavior Research Methods, 37(4), 665-671.

De Bleser, R., Dupont, P., Postler, J., Bormans, G., Speelman, D., Mortelmans, L., \& Debrock, M. (2003). The organisation of the bilingual lexicon: a PET study. Journal of Neurolinguistics, 16(4), 439-456. https://doi.org/10.1016/S0911-6044(03)00022-8

Dehaene, S., Dupoux, E., Mehler, J., Cohen, L., Paulesu, E., Perani, D., van de Moortele, P. F., Lehéricy, S., \& Le Bihan, D. (1997). Anatomical variability in the cortical representation of first and second language. Neuroreport, 8(17), 3809-3815.

Dijkstra, A. F. J., Haga, F., Bijsterveld, A., \& Sprinkhuizen-Kuyper, I. G. (2012). Lexical competition in localist and distributed connectionist models of L2 acquisition. In J. Altarriba \& L. Isurin (Eds.), Memory, Language, and Bilingualism: Theoretical and Applied Approaches. Cambridge University Press. http://repository.ubn.ru.nl/handle/2066/101834

Dijkstra, T., \& Van Heuven, W. J. (2002). The architecture of the bilingual word recognition system: From identification to decision. Bilingualism: Language and Cognition, 5(3), 175-197. 
Dijkstra, T., Wahl, A., Buytenhuijs, F., Halem, N. V., Al-Jibouri, Z., Korte, M. D., \& Rekké, S. (2019). Multilink: a computational model for bilingual word recognition and word translation. Bilingualism: Language and Cognition, 22(4), 657-679. https://doi.org/10.1017/S1366728918000287

Durda, K., \& Buchanan, L. (2008). WINDSOR: Windsor improved norms of distance and similarity of representations of semantics. Behavior Research Methods, 40(3), 705-712. https://doi.org/10.3758/BRM.40.3.705

Evans, A. C., Collins, D. L., \& Milner, B. (1992). An MRI-based stereotactic atlas from 250 young normal subjects. Soc. Neurosci. Abstr, 18, 408.

Ferreira, R. A., Göbel, S. M., Hymers, M., \& Ellis, A. W. (2015). The neural correlates of semantic richness: Evidence from an fMRI study of word learning. Brain and Language, 143, 6980. https://doi.org/10.1016/j.band1.2015.02.005

Forman, S. D., Cohen, J. D., Fitzgerald, M., Eddy, W. F., Mintun, M. A., \& Noll, D. C. (1995). Improved assessment of significant activation in functional magnetic resonance imaging (fMRI): use of a cluster-size threshold. Magnetic Resonance in Medicine: Official Journal of the Society of Magnetic Resonance in Medicine / Society of Magnetic Resonance in Medicine, 33(5), 636-647.

Gagnepain, P., Chételat, G., Landeau, B., Dayan, J., Eustache, F., \& Lebreton, K. (2008). Spoken word memory traces within the human auditory cortex revealed by repetition priming and functional magnetic resonance imaging. The Journal of Neuroscience, 28(20), 5281-5289. https://doi.org/10.1523/JNEUROSCI.0565-08.2008

Grainger, J., Midgley, K. J., \& Holcomb, P. J. (2010). Re-thinking the bilingual interactiveactivation model from a developmental perspective (BIA-d). In M. kail \& M. Hickmann, Language Acquisition and Language Disorders (pp. 267-283). John Benjamins Publishing Company. https://benjamins.com/catalog/lald.52.18gra

Green, D. W. (2003). Neural basis of lexicon and grammar in L2 acquisition: The convergence hypothesis. In R. van Hout, A. Hulk, F. Kuiken, \& R. Towell (Eds.), The lexicon-syntax 
interface in second language acquisition. (pp. 197-218). John Benjamins. http://eprints.ucl.ac.uk/164901/

Green, D. W., \& Abutalebi, J. (2013). Language control in bilinguals: The adaptive control hypothesis. Journal of Cognitive Psychology, 25(5), 515-530. https://doi.org/10.1080/20445911.2013.796377

Green, D. W., \& Abutalebi, J. (2015). Language control and the neuroanatomy of bilingualism: in praise of variety. Language, Cognition and Neuroscience, $0(0), 1-5$. https://doi.org/10.1080/23273798.2015.1084428

Grinband, J., Wager, T. D., Lindquist, M., Ferrera, V. P., \& Hirsch, J. (2008). Detection of timevarying signals in event-related fMRI designs. NeuroImage, 43(3), 509-520. https://doi.org/10.1016/j.neuroimage.2008.07.065

Grosjean, F. (2010). Bilingual: Life and Reality. Harvard University Press.

Guasch, M., Boada, R., Ferré, P., \& Sánchez-Casas, R. (2012). NIM: A Web-based Swiss army knife to select stimuli for psycholinguistic studies. Behavior Research Methods, 45(3), 765771. https://doi.org/10.3758/s13428-012-0296-8

Hernandez, A. E., \& Li, P. (2007). Age of acquisition: Its neural and computational mechanisms. Psychological Bulletin, 133(4), 638-650. https://doi.org/10.1037/0033-2909.133.4.638

Hsu, C.-T., Jacobs, A. M., \& Conrad, M. (2015). Can Harry Potter still put a spell on us in a second language? An fMRI study on reading emotion-laden literature in late bilinguals. Cortex, 63, 282-295. https://doi.org/10.1016/j.cortex.2014.09.002

Humphries, C., Sabri, M., Lewis, K., \& Liebenthal, E. (2014). Hierarchical organization of speech perception in human auditory cortex. Frontiers in Neuroscience, 8. https://doi.org/10.3389/fnins.2014.00406

Indefrey, P. (2006). A meta-analysis of hemodynamic studies on first and second language processing: Which suggested differences can we trust and what do they mean? Language Learning, 56, 279-304. https://doi.org/10.1111/j.1467-9922.2006.00365.x 
Jamal, N. I., Piche, A. W., Napoliello, E. M., Perfetti, C. A., \& Eden, G. F. (2012). Neural basis of single-word reading in Spanish-English bilinguals. Human Brain Mapping, 33(1), 235245. https://doi.org/10.1002/hbm.21208

Jefferies, E. (2013). The neural basis of semantic cognition: Converging evidence from neuropsychology, neuroimaging and TMS. Cortex, 49(3), 611-625. https://doi.org/10.1016/j.cortex.2012.10.008

Jenkinson, M, \& Smith, S. (2001). A global optimisation method for robust affine registration of brain images. Medical Image Analysis, 5(2), 143-156.

Jenkinson, M., Bannister, P., Brady, M., \& Smith, S. (2002). Improved optimization for the robust and accurate linear registration and motion correction of brain images. NeuroImage, 17(2), $825-841$

Kim, S. Y., Qi, T., Feng, X., Ding, G., Liu, L., \& Cao, F. (2016). How does language distance between L1 and L2 affect the L2 brain network? An fMRI study of Korean-ChineseEnglish $\quad$ trilinguals. $\quad$ NeuroImage, $\quad 129, \quad 25-39$. https://doi.org/10.1016/j.neuroimage.2015.11.068

Kroll, J. F., \& Bialystok, E. (2013). Understanding the consequences of bilingualism for language processing and cognition. Journal of Cognitive Psychology (Hove, England), 25(5). https://doi.org/10.1080/20445911.2013.799170

Kroll, J. F., \& Stewart, E. (1994). Category interference in translation and picture naming: Evidence for asymmetric connections between bilingual memory representations. Journal of Memory and Language, 33(2), 149-174. https://doi.org/10.1006/jmla.1994.1008

Kroll, J. F., Van Hell, J. G., Tokowicz, N., \& Green, D. W. (2010). The Revised Hierarchical Model: A critical review and assessment. Bilingualism: Language and Cognition, 13(03), 373-381.

Kuznetsova, A., Brockhoff, P. B., \& Christensen, R. H. (2017). lmerTest package: Tests in linear mixed effects models. Journal of Statistical Software, 82(13), 1-26. 
Lambon Ralph, M. A., Jefferies, E., Patterson, K., \& Rogers, T. T. (2017). The neural and computational bases of semantic cognition. Nature Reviews Neuroscience, 18(1), 42-55. https://doi.org/10.1038/nrn.2016.150

Lemhöfer, K., \& Broersma, M. (2012). Introducing LexTALE: A quick and valid lexical test for advanced learners of English. Behavior Research Methods, 44(2), 325-343. https://doi.org/10.3758/s13428-011-0146-0

Li, H., Qu, J., Chen, C., Chen, Y., Xue, G., Zhang, L., Lu, C., \& Mei, L. (2019). Lexical learning in a new language leads to neural pattern similarity with word reading in native language. Human Brain Mapping, 40(1), 98-109. https://doi.org/10.1002/hbm.24357

Li, P., Sepanski, S., \& Zhao, X. (2006). Language history questionnaire: A Web-based interface for bilingual research. Behavior Research Methods, 38(2), 202-210. https://doi.org/10.3758/BF03192770

Liu, H., \& Cao, F. (2016). L1 and L2 processing in the bilingual brain: A meta-analysis of neuroimaging studies. Brain and Language, 159, 60-73. https://doi.org/10.1016/j.bandl.2016.05.013

Liu, Y., Dunlap, S., Fiez, J., \& Perfetti, C. (2007). Evidence for neural accommodation to a writing system following learning. Human Brain Mapping, 28(11), 1223-1234. https://doi.org/10.1002/hbm.20356

Luk, G., Green, D. W., Abutalebi, J., \& Grady, C. (2011). Cognitive control for language switching in bilinguals: A quantitative meta-analysis of functional neuroimaging studies. Language and Cognitive $\quad$ Processes, 27(10), 1479-1488. https://doi.org/10.1080/01690965.2011.613209

Marian, V., Shildkrot, Y., Blumenfeld, H. K., Kaushanskaya, M., Faroqi-Shah, Y., \& Hirsch, J. (2007). Cortical activation during word processing in late bilinguals: Similarities and differences as revealed by functional magnetic resonance imaging. Journal of Clinical and Experimental Neuropsychology, 29(3), 247-265. https://doi.org/10.1080/13803390600659376 
Meade, G., \& Dijkstra, T. (2017). Mechanisms underlying word learning in second language acquisition. In M. Libben, M. Goral, \& G. Libben, Bilingualism. A framework for understanding the mental lexicon (pp. 49-72). John Benjamins Publishing Company.

Mirman, D., \& Magnuson, J. S. (2008). Attractor dynamics and semantic neighborhood density: Processing is slowed by near neighbors and speeded by distant neighbors. Journal of Experimental Psychology. Learning, Memory, and Cognition, 34(1), 65-79. https://doi.org/10.1037/0278-7393.34.1.65

Nagel, I. E., Schumacher, E. H., Goebel, R., \& D’Esposito, M. (2008). Functional MRI investigation of verbal selection mechanisms in lateral prefrontal cortex. NeuroImage, 43(4), 801-807. https://doi.org/10.1016/j.neuroimage.2008.07.017

Nelson, J. R., Liu, Y., Fiez, J., \& Perfetti, C. A. (2009). Assimilation and accommodation patterns in ventral occipitotemporal cortex in learning a second writing system. Human Brain Mapping, 30(3), 810-820. https://doi.org/10.1002/hbm.20551

Oldfield, R. C. (1971). The assessment and analysis of handedness: the Edinburgh inventory. Neuropsychologia, 9(1), 97-113.

Paradis, M. (1995). Aspects of bilingual aphasia. Pergamon.

Paradis, M. (2004). A Neurolinguistic Theory of Bilingualism. John Benjamins Publishing Company.

Paradis, M. (2009). Declarative and procedural determinants of second languages (Vol. 40). John Benjamins Publishing.

Paradis, M., Goldblum, M.-C., \& Abidi, R. (1982). Alternate antagonism with paradoxical translation behavior in two bilingual aphasic patients. Brain and Language, 15(1), 55-69. https://doi.org/10.1016/0093-934X(82)90046-3

Patterson, K., Nestor, P. J., \& Rogers, T. T. (2007). Where do you know what you know? The representation of semantic knowledge in the human brain. Nature Reviews Neuroscience, 8(12), 976-987. https://doi.org/10.1038/nrn2277 
Peeters, D., Vanlangendonck, F., Rueschemeyer, S. A., \& Dijkstra, T. (2019). Activation of the language control network in bilingual visual word recognition. Cortex, 111, 63-73. https://doi.org/10.1016/j.cortex.2018.10.012

Perani, D, Dehaene, S., Grassi, F., Cohen, L., Cappa, S. F., Dupoux, E., Fazio, F., \& Mehler, J. (1996). Brain processing of native and foreign languages. Neuroreport, 7(15-17), 24392444.

Perani, D., Paulesu, E., Galles, N. S., Dupoux, E., Dehaene, S., Bettinardi, V., Cappa, S. F., Fazio, F., \& Mehler, J. (1998). The bilingual brain. Proficiency and age of acquisition of the second language. Brain, 121(10), 1841-1852. https://doi.org/10.1093/brain/121.10.1841

Perani, D., \& Abutalebi, J. (2005). The neural basis of first and second language processing. Current Opinion in Neurobiology, 15(2), 202-206. https://doi.org/10.1016/j.conb.2005.03.007

Perani, D., Abutalebi, J., Paulesu, E., Brambati, S., Scifo, P., Cappa, S. F., \& Fazio, F. (2003). The role of age of acquisition and language usage in early, high-proficient bilinguals: An fMRI study during verbal fluency. Human Brain Mapping, 19(3), 170-182. https://doi.org/10.1002/hbm.10110

R Core Team. (2017). R: A language and environment for statistical computting. R Foundation for Statistical Computing. Vienna, Austria. https://www.r-project.org/

Sun, Y., Peng, D., Ding, G., Qi, T., Desroches, A. S., \& Liu, L. (2015). The dynamic nature of assimilation and accommodation procedures in the brains of Chinese-English and EnglishChinese bilinguals. Human Brain Mapping, 36(10), 4144-4157. https://doi.org/10.1002/hbm.22904

The British National Corpus, version 3 (BNC XML Edition). (2007). Distributed by Oxford University Computing Services on behalf of the BNC Consortium. http://www.natcorp.ox.ac.uk/ 
Thompson-Schill, S. L., D’Esposito, M., Aguirre, G. K., \& Farah, M. J. (1997). Role of left inferior prefrontal cortex in retrieval of semantic knowledge: a reevaluation. Proceedings of the National Academy of Sciences of the United States of America, 94(26), 14792-14797.

Ullman, M. T. (2001). A neurocognitive perspective on language: The declarative/procedural model. Nature Reviews Neuroscience, 2(10), 717-726.

Ullman, M. T. (2005). A cognitive neuroscience perspective on second language acquisition: The declarative/procedural model. Mind and Context in Adult Second Language Acquisition, $141-178$.

Van de Putte, E., De Baene, W., Brass, M., \& Duyck, W. (2017). Neural overlap of L1 and L2 semantic representations in speech: A decoding approach. NeuroImage, 162, 106-116. https://doi.org/10.1016/j.neuroimage.2017.08.082

Van de Putte, E., De Baene, W., Price, C. J., \& Duyck, W. (2018). Neural overlap of L1 and L2 semantic representations across visual and auditory modalities: a decoding approach. Neuropsychologia, 113, 68-77. https://doi.org/10.1016/j.neuropsychologia.2018.03.037

Van Hell, J. G., \& De Groot, A. M. B. (1998). Conceptual representation in bilingual memory: Effects of concreteness and cognate status in word association. Bilingualism: Language and Cognition, 1(03), 193-211. https://doi.org/10.1017/S1366728998000352

van Heuven, W. J. B., \& Dijkstra, T. (2010). Language comprehension in the bilingual brain: fMRI and ERP support for psycholinguistic models. Brain Research Reviews, 64(1), 104-122. https://doi.org/10.1016/j.brainresrev.2010.03.002

Videsott, G., Herrnberger, B., Hoenig, K., Schilly, E., Grothe, J., Wiater, W., Spitzer, M., \& Kiefer, M. (2010). Speaking in multiple languages: Neural correlates of language proficiency in multilingual word production. Brain and Language, 113(3), 103-112. https://doi.org/10.1016/j.band1.2010.01.006

Vigliocco, G., Kousta, S.-T., Rosa, D., Anthony, P., Vinson, D. P., Tettamanti, M., Devlin, J. T., \& Cappa, S. F. (2014). The neural representation of abstract words: The role of emotion. Cerebral Cortex, 24(7), 1767-1777. https://doi.org/10.1093/cercor/bht025 
Wagner, A. D., Paré-Blagoev, E. J., Clark, J., \& Poldrack, R. A. (2001). Recovering meaning: left prefrontal cortex guides controlled semantic retrieval. Neuron, 31(2), 329-338.

Warrier, C., Wong, P., Penhune, V., Zatorre, R., Parrish, T., Abrams, D., \& Kraus, N. (2009). Relating structure to function: Heschl's Gyrus and acoustic processing. The Journal of Neuroscience, 29(1), 61-69. https://doi.org/10.1523/JNEUROSCI.3489-08.2009

Wilson, M. (1988). MRC psycholinguistic database: Machine-usable dictionary, version 2.00. Behavior Research Methods, Instruments, \& Computers, 20(1), 6-10. https://doi.org/10.3758/BF03202594

Woolrich, M. W., Ripley, B. D., Brady, M., \& Smith, S. M. (2001). Temporal autocorrelation in univariate linear modeling of FMRI data. NeuroImage, 14(6), 1370-1386. https://doi.org/10.1006/nimg.2001.0931

Worsley, K. J. (2001). Statistical analysis of activation images. Functional MRI: An Introduction to Methods, 14, 251-270. 